\title{
Analysis of Tubular-type Linear Generator for Free-Piston Engine
}

\author{
Sun-Ki Hong ${ }^{1}$, Ho-Yong Choi ${ }^{2}$, \\ Jae-Won Lim², Hyo-Jae $\operatorname{Lim}^{1}$ and Hyun-Kyo Jung ${ }^{2}$
}

${ }^{1}$ Dept. of Information \& Control, ${ }^{1+}{ }^{\dagger}$ Dept. of Mechanics, Hoseo University, Baebang-myun, Asan, Chungnam, 336-795, KOREA

Phone +82-41-540-5674, E-mail: ${ }^{1}$ skhong@hoseo.edu, ${ }^{1}{ }^{\dagger}$ hjlim@office.hoseo.ac.kr

, ${ }^{2}$ School of Electrical Engineering, Seoul National University, Shillim-Dong, Kwanak-Gu, Seoul, KOREA,

Phone +82-2-880-7262, Fax +82-2-878-1452

\begin{abstract}
Tubular-type linear generator for the free-piston engine is anlayzed using finite element method and its characteristics are explaind. Magnetic characteristics of the linear generator are calculated using the finite element method and various structures are considered to achieve the lowest detent force within the rated voltage. The path of the magnetic flux is constructed by the axially magnetized magnets and the iron pole, and the detent force is minimized by adjusting the width of the magnet pole.
\end{abstract}

\section{Key words}

Linear generator, Free-piston engine, Detent force, Tubular-type linear generator, finite element method

\section{Introduction}

The free-piston engine system has high efficiency and reliability in the energy conversion process because of the absence of the mechanical devices like a crankshaft, a connecting rod, etc. The linear generator plays a very important role in this free-piston engine system to realize high efficient system [1],[2].

In this research, the tubular-type linear generator for the free-piston engine is analyzed and designed. The tubular-type generator has higher efficiency and reliability than the flat-type one because of its structural merits. The amount of the leakage flux is small and the rotation of the piston does not affect the electric characteristics of the linear generator [3]-[6]. For the stable operation of the linear generator, the detent force should be minimized. The detent force is minimized by varying the magnetic pole pitch. This method can reduce the detent force and also improve the output waveform. The modified pole pitch values are optimized and then the tubular-type linear generator is designed. The stroke, frequency, number of poles and phases are determined by the conditions of the free-piston engine and the machine controller. In this research, $1[\mathrm{~kW}], 2$-pole, 3-phase linear generator is analyzed and designed. The stroke of the machine is $72[\mathrm{~mm}]$ and the operating frequency is $30[\mathrm{~Hz}]$. The finite element method is used to analyze the magnetic characteristics of the generator. The back-emf and detent force characteristics are simulated and the optimized design factors of the generator are derived from those results.

\section{Design of the Linear Generator}

\section{A. Tubular-type Linear Generator}

Fig. 1 shows a cut-away view of the tubular-type linear generator. The machine of this research consists of the coil-wounded stator and the permanent magnet mover. The ring magnets on the cylindrical mover is axially magnetized and the iron poles make the magnetic flux paths. The radial magnets or Halbach array magnets could be used, however, for simple structure in this research, the ring shaped iron pole is used instead of the magnet pole.

The tubular-type linear generator has some better qualities than the flat-type one. Because of the symmetric structure, the leakage is smaller than that of the flat-type one. Also, the amount of coil is less and there is no end coil, therefore the copper loss becomes less than that of flat type generator. The shaft is cylindrical and it can be easily connected with the rod of the engine piston without complex mechanical structure. Furthermore, the cylindrical mover can be rotated freely with the piston of the engine and there is no interference to the magnetic characteristics in this structure.

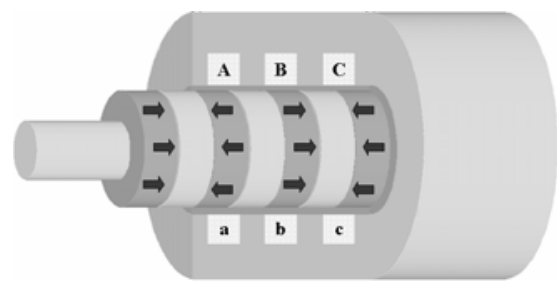

Fig. 1. Cut-away View of the Tubular-type Linear Generator 


\section{B. Specification of the Linear Generator}

Table 1 shows the specifications of the linear generator in this research. The rated output is $1[\mathrm{~kW}]$ and the stroke of the linear generator, $72[\mathrm{~mm}]$, is limited by the free-piston engine stroke and the operation frequency, $30[\mathrm{~Hz}]$, is that of the hydrogen engine. The maximum output voltage is $300[\mathrm{~V}]$, which is limited by the control circuit elements.

From the mechanical size of the free-piston engine, the proper size of the linear generator is selected. There are two modules of 2-pole mover and three modules of 3-phase stator coil.

TABLE 1. SPECIFICATIONS OF THE LINEAR GENERATOR

\begin{tabular}{cc}
\hline Output & $1[\mathrm{~kW}]$ \\
\hline Pole/phase & 2 pole/ 3 phase \\
\hline Stroke & $72[\mathrm{~mm}]$ \\
\hline Frequency & $30[\mathrm{~Hz}]$ \\
\hline Maximum Output Voltage & $300[\mathrm{~V}]$ \\
\hline
\end{tabular}

\section{Back-EMF Analisys}

The stroke of the linear generator is short and the operation frequency is high so that the velocity of the mover is not constant. In the design process, a sinusoidal velocity profile of the mover is assumed. At both end sides, the velocity of the mover is zero and the velocity is the maximum value at the center of the stroke. In this case, the maximum velocity of the mover is over $6[\mathrm{~m} / \mathrm{s}]$ and the average velocity is about $4.3[\mathrm{~m} / \mathrm{s}]$. Under this velocity profile, the sinusoidal output waveform is preferred and the maximum output line to line voltage should be under $300[\mathrm{~V}]$.

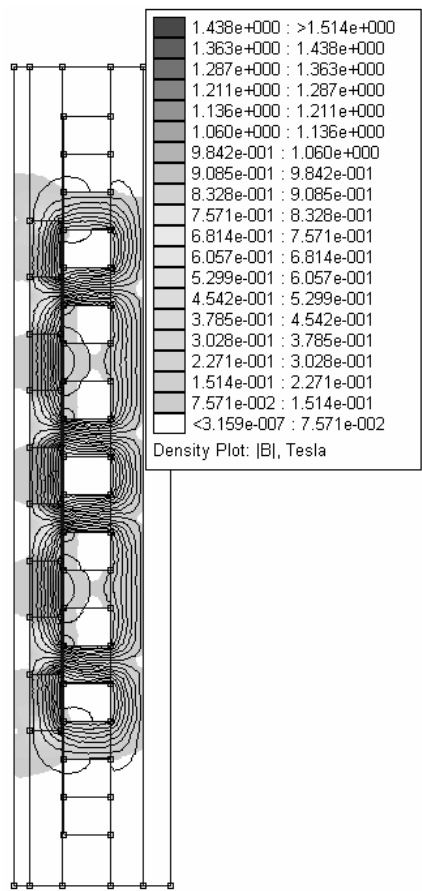

Fig. 2. Magnetic Flux Density of Tubular Linear Generator
The finite element method is used to analyze the magnetic characteristics of the linear generator. Fig. 2 shows the magnetic flux density and equi-potential lines as the result of the axis-symmetric analysis of the test model.

The result of the phase voltage analysis with the sinusoidal velocity profile is presented in Fig. 3 . The output line-to-line voltage is shown in Fig. 4. The final output waveform to the output circuit after the regulation process becomes the largest envelopes of each phase voltage. The maximum value of the output voltage is not enough and the shape is somewhat little sinusoidal. A new design which can increase the output voltage and can get more sinusoidal waveform is needed to satisfy the required specifications.

\section{Detent Force Reduction}

The maximum detent force of the basic linear generator model is about $70[\mathrm{~N}]$. This is a relatively large value compared to the rated reaction force of the test model, which is about $250[\mathrm{~N}]$. For the stable operation of the free-piston engine system, small detent force of the linear generator is required.

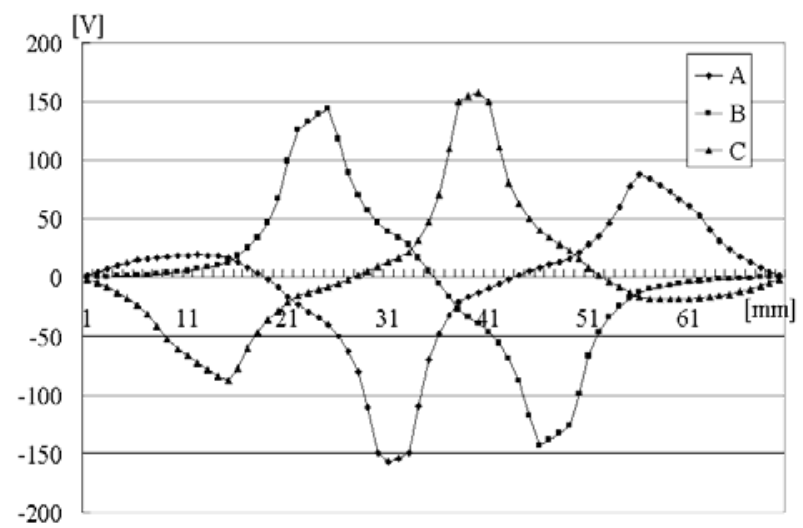

Fig. 3. Phase Voltage with the Sinusoidal Velocity

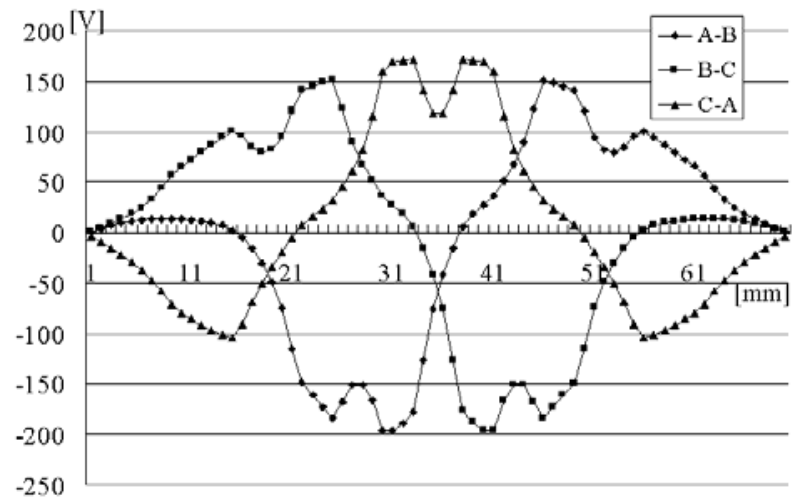

Fig. 4. Line-to-line Voltage

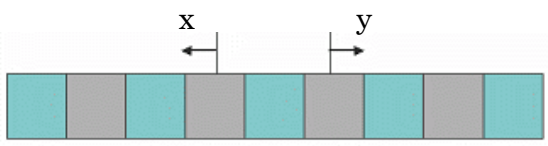

Fig. 5. Pole pitch modulation of mover 
There are many conventional detent force reduction methods like the skew, chamfering, adjusting pole width, etc. However, in this case, those methods cannot gurantee good perfromances of both the output voltage and the detent force. To realize the high output voltage and the small detent force, irregular pole pitch is adopted to the mover. By changing some pole pitch, some harmonics cancel each other and the total detent force can be reduced. Though, in a normal case, the irregular pole pitch can cause a phase unbalance problem or the reduction of the peak voltage. The output waveform and the peak value is improved in this case.

The detent force decreases or increases with the variations of the pole pitch $\mathrm{x}$ and $\mathrm{y}$. Fig. 5 shows the pole pitch modulation. In the case of $x=3$, the detent force has the smallest value. After fixing $x$ to 3 , the detent forces with the variations of $y$ is calculated. The detent force is smallest when $y=-3$. Fig. 6 shows the simulation results of the detent force distribution with the variation of $y$ when $x=3$. Fig. 7 shows the output voltage waveforms which are regulated. In the case of $y=-3$, though the peak value of the output voltage decreases little, the total waveform is more sinusoidal and this result is acceptable. In conclusion, the irregular pole pitch is very useful to realize the small detent force and the sinusoidal output waveform in this research. Furthermore, the manufacturing feasibility of this method is good.

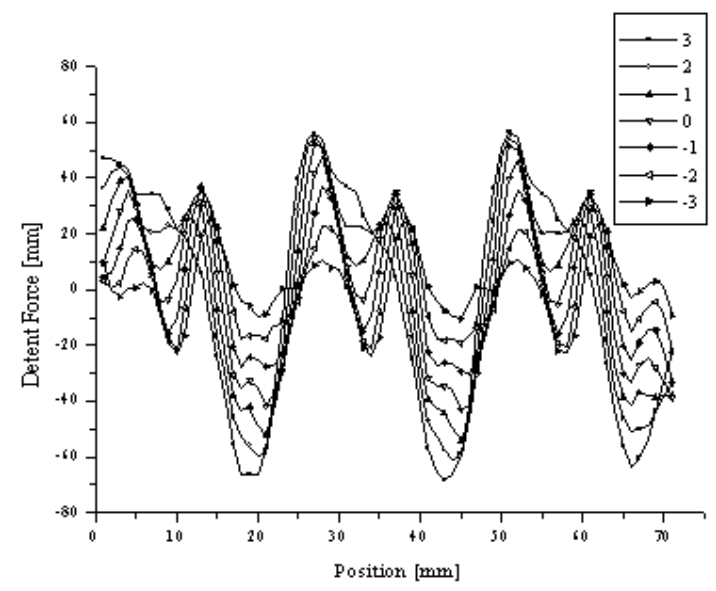

Fig. 6. Detent force distribution with the variation of $y(x=3)$

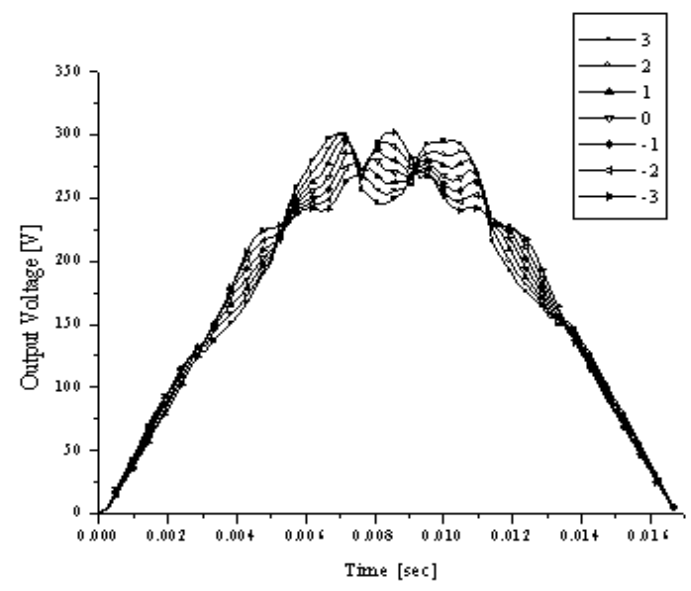

Fig. 7. Output Voltages with the Variations of $y(x=3)$

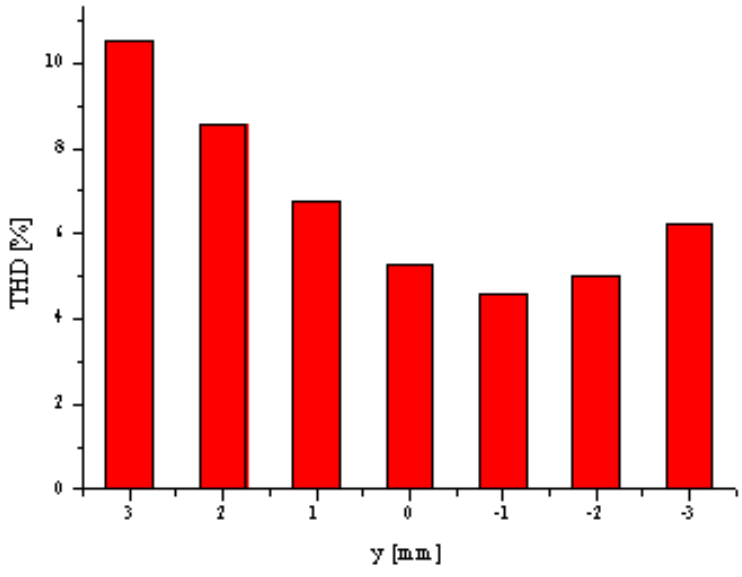

Fig. 8. THD with the varation of $y($ when $x=3)$

Fig. 8 shows the THD with the varation of $y$ when $x=3$. When $\mathrm{y}=3$, THD $=10.57[\%]$ and when $\mathrm{y}=-3$ THD becomes 6.23[\%], which is not smallest value, however $\mathrm{y}=$ 3 is selected because the detent force is smallest at this point.

From these simulation results, the tubular type linear synchronous generator is manufactured. In the manufacturing process, tubular type has more difficulties than planer type, however, tubular type has many merits like efficiency and power rate etc.

\section{Experimental Results}

Fig. 9 shows the manufactured mover of the tubular type linear generator. The middle part of the mover becomes the permanent magnets and magnetic path ring. Fig. 10 shows the assembled tubular type linear generator and experimental devices. The mover is supported by the linear bushing which is attached each sides of stator. For the first step of experiment, rotary type induction motor is used instead of the free piston engine, and crank structure is employed for conversing rotating motion to rectilinear motion. For reducing mechanical stress which is comes from the vibration of the mover, fan shaped crank structure is applied. The shaft is connected to crank structure and one side of connecting rod is linked to linear guide for supporting connecting part. Linear guide also helps giving no normal force in linear bushing.

Fig. 11 shows the comparison of the simulation and experments for no-load back emf. As can be seen in the figure, the experimental results have good agreement with the simulation. Fig. 12 shows the back emf wave form for full load.

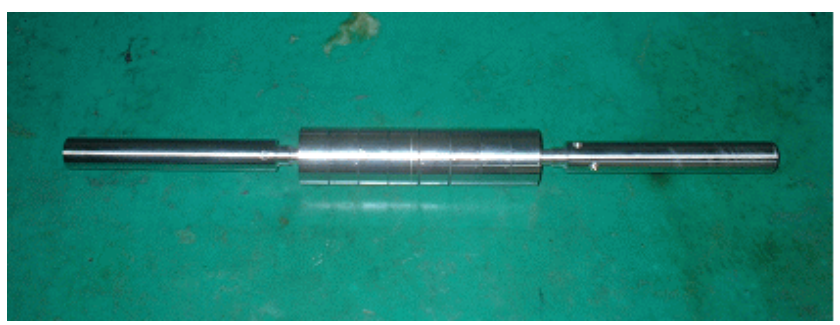

Fig. 9. Manufactured mover 


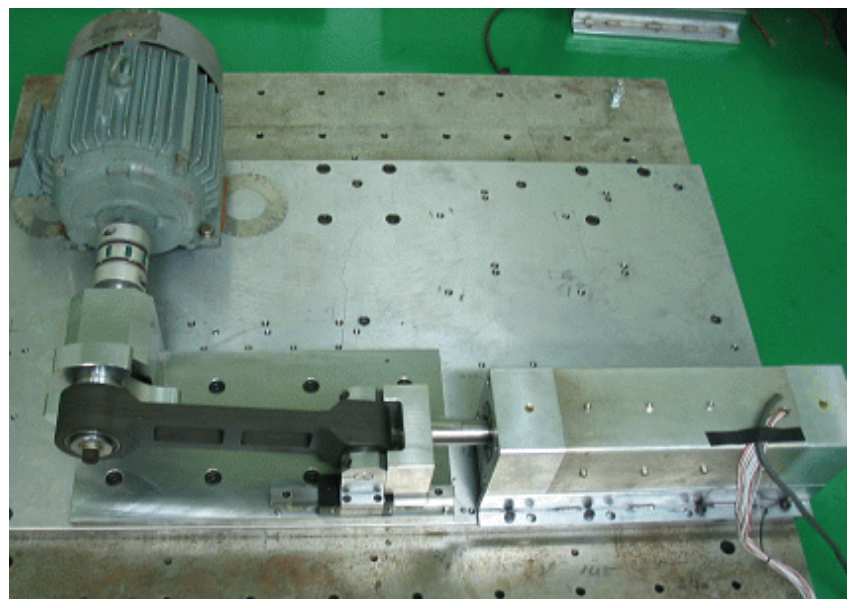

Fig. 10. Assembled linear generator and experimental setup.

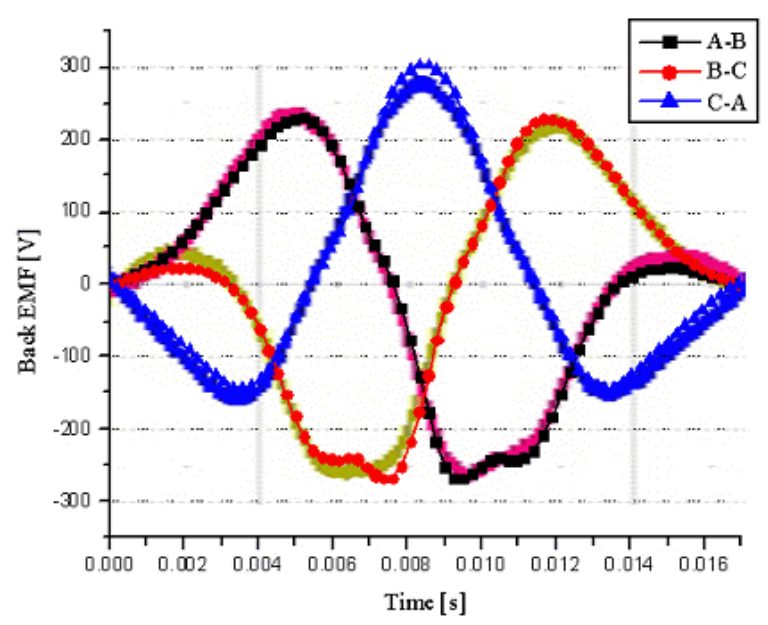

Fig. 11. Output voltage with no load

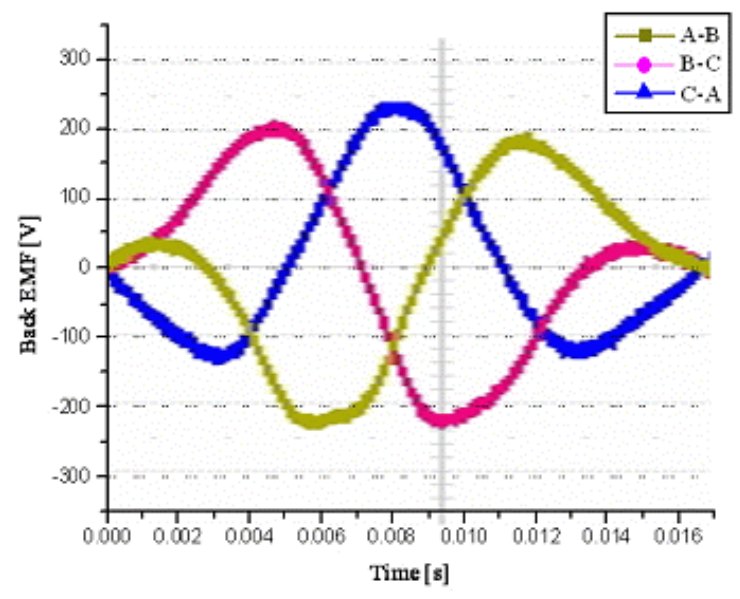

Fig. 12. Output voltage with full load

\section{Conclusion}

In this paper, tubular-type linear generator for free-piston engine system of high efficiency is analyzed and compared the simulation results with the experiments. The ring-shaped iron with axially magnetized magnet rather than radial type magnet is used as the magnetic pole of the mover because the ring shape for the manufacturing feasibility and the low price. To realize small detent force and sinusoidal output waveform of the linear generator, the irregular pole pitch is adapted in this research. The irregular pole pitch gives merits to producing more sinusoidal waveform as well as reducing the detent force. The generator is manufactured and tested with some experimental devices and the results show good agreements with the simulations.

\section{Acknowledgement}

This work was partly supported by grant No. RTI04-01-01 from the Regional Technology Innovation Program of the Ministry of Commerce, Industry and Energy(MOCIE).

\section{References}

[1] Waqas M. Arshad, Thomas Backstrom, Peter Thelin and Chandur Sadarangani : "Integrated free-piston generators : an overview”, Electrical Vehicle Symposium, 2002

[2] William R. Cawthorne : "Optimization of a brushless permanent magnet linear alternator for use with a linear internal combustion engine”, West Virginia University, 1999

[3] A. Cosic, J. Lindback, W. M. Arshad, M. Leksell, P. Thelin, E. Nordlund : "Application of a free-piston generator in a series hybrid vehicle”, LDIA, 2003

[4] Waqas M. Arshad, Chandur Sadarangani, Thomas Backstrom and Peter Thelin : Finding an appropriate electrical machine for a free piston generator", Electrical Vehicle Symposium, 2002

[5] Ho-Yong Choi, Jae-Won Lim, Hyun-Kyo Jung, Sun-Ki Hong, Dong-Hyeok Cho, Sang-Yeon Hwang, Si-Doek Oh : "Design of Flat-type Linear Generator for Free-Piston Engine”, ICEMS, 2004

[6] Ho-Yong Choi, Sang-Yong Jung, Hyun-Kyo Jung : "Performance evaluation of permanent magnet linear generator for charging the battery of mobile apparatus”, LDIA, 2001

[7] Jae-Won Lim, Ho-Yong Choi, Hyun-Kyo Jung, Sun-Ki Hong, Chul-Gyun Lee, "Shape Optimization of Teeth Structure in Tubular-Type Linear Gnerator”, pp.148-151, LDIA 2005 